\title{
The Junior College Library as an Audio-Visual Center
}

\begin{abstract}
Recognizing that centralization of a junior college's audio-visual facilities is economical and efficient, this paper presents the case for placing them under the supervision of the librarian. Library personnel with special training or orientation are necessary, if audio-visual facilities are to function properly. They also require special space, equipment, and budgetary support. Principles of administration of audiovisual centers are enumerated, and guidelines to their satisfactory management for maximum value to their users are detailed. Practices in acquiring, storing, and handling of audio-visual materials to their greatest enhancement are described. Suggestions are made for encouraging increased use of A-V materials by students and instructors.
\end{abstract}

$\mathrm{J}$ UNIOR COLLEGES have a reputation in many circles for good teaching. If instruction can be made more effective and efficient through the use of audiovisual aids, then audio-visual materials and equipment should be employed on the junior college level and schemes for increasing their use should be sought and found. National standards for junior college libraries state that "audio-visual materials are an important part of modern instruction. They can play a major role in the learning process by supplementing books and other printed materials. They should be ordered, housed, and administered in the library unless another department on the campus is effectively executing this program."1

${ }^{1}$ ACRL, "Standards for Junior College Libraries," CRL, XXI (May 1960), 204.

Mrs. Christensen is Education Librarian at John F. Kennedy memorial library, California State College at Los Angeles. This paper was read to the meeting of the Junior College Libraries Section of ACRL at ALA Chicago Conference, July 18, 1963.
The desirability of the library serving as a center for audio-visual aids comes from the concept of the unity of instructional materials regardless of format. Louis Shores, a leading spokesman for this idea, holds that "there is one world of instructional materials, not a trichotomy of audio-visual, library, and textbook kingdoms." 2 To him, content is what is important, not the format.

Designating the college library as an audio-visual center is not a traditional practice. The idea may be said to date from 1946, when a postwar planning committee of college and university librarians recommended the library as "the logical agency to handle these teaching aids." ${ }^{3}$ A survey conducted six years later in 1952 showed that only 15 per cent of the 575 institutions responding to a questionnaire had centralized

\footnotetext{
2 Louis Shores, "Union Now-The A-V Way and the Library Way," Educational Screen, XXXIV (March 1955), 112.

3 As quoted by Guy R. Lyle, The Administration of the College Library (3d ed. New York: H. W. Wilson Co., 1961), p.302.
} 
their audio-visual service in the library. ${ }^{4}$ This same survey indicated that institutions in the Southwest showed a greater tendency toward centralized administration of audio-visual services than those in other regions; also, junior colleges had tended more to centralize services in the library than had either teacher-training or graduate institutions. The larger the institution, the more likely that audio-visual services would be centralized. ${ }^{5}$ A survey of audio-visual programs in California junior colleges based on the 1956-57 academic year found that about 50 per cent of the colleges had their audio-visual services under the administration of the library. ${ }^{6}$

Current practices in the audio-visual programs of California's junior colleges vary a great deal, and local factors are important determinants. In the fall of 1961 Foothill College moved to a new campus where the library covers almost an acre and houses an audio-visual center that features two hundred stereophonic $^{7}$ listening stations. On the other hand, audio-visual service at Santa Monica City College is limited to checking out supplemental equipment from an audio-visual room which may also be used for previewing materials. No audiovisual materials are handled by that library, although instructors may draw on the resources of the school district's instructional materials center. ${ }^{8}$

There are many theoretical advantages to having centralized service under the administration of the library. For example, it represents good administrative organization, for it fixes responsibility in one department and avoids the confusion and overlapping of separate agen-

\footnotetext{
- Fleming Bennett, "Audio-Visual Services in Colleges and Universities in the United States ...." CRL, XVI (January 1955), 11.

${ }^{5}$ Ibid., p.12.

- John Wetzler, "A Survey of California Junior College Audio-Visual Programs," Junior College Journal, XXIX (February 1959), 332-33.

${ }^{7}$ News item in the Foothill Sentinel, June 9, 1961.

8 "Santa Monica City College Faculty Handbook, 1960-61." (Processed.)
}

cies. Centralization gives order and direction to the procurement of materials and equipment and makes possible a single catalog of all instructional materials. Central control lends itself to one charging and booking system for all materials. Also, the servicing of materials and equipment can be better coordinated.

The unity of materials regardless of format is an asset to instruction. It is educationally advantageous to have all instructional materials in one place. Centralization increases use and improves instruction. It is economically sound and it contributes to the efficiency of school operations. It eliminates duplication of effort and reduces waste.

These materials lend themselves to the library processes of acquisition, preparation, interpretation, and dissemination. The library is already involved with audio-visual aids to a certain extent, and librarians have many understandings and skills related to handling printed materials that will transfer to the handling of audio-visual aids. The librarian's training in organization and cataloging insures that materials will be properly indexed and circulated. When the library serves as an audio-visual center, the necessary technical direction is more apt to be provided, and the equipment is likely to be safer from tampering and theft while at the same time receiving regular attention to keep it in working condition.

Another advantage to centralizing audio-visual services in the library is that it tends to increase instructor-librarian collaboration through the many opportunities offered for working together on the audio-visual program. Such contacts promote a better understanding of the respective roles of librarians and instructors in the educational process. Both students and faculty are best served by a single center, whereas separation is artificial and confusing to 
users. Centralized facilities provide onestop service where ideas can be tracked down in various forms or media. An audio-visual desk always staffed and available for service is convenient and saves time and energy for all concerned.

Audio-visual materials and their organization can develop proportionally along with other materials and methods for learning. Increased use of audio-visual materials is usually accompanied by increased use of the printed word. Library audio-visual centers tend to include all recognized audio-visual materials whereas nonlibrary agencies sometimes focus on certain forms of materials. Actually it is almost impossible to tell where library materials leave off and audio-visual materials begin. The interrelationship among all instructional materials makes housing together the best policy.

There are, however, some major problems in making the library an audiovisual center. The administration, organization, and operation of such a service is a complex undertaking. Merely placing it in the library will not insure its success. Without the "right" personnel, the library serving as an audio-visual center will not be effective in practice.

Closely related to the personnel problem is the attitude of the staff toward audio-visual media. Some librarians fear these aids as enemies of reading. The gadgetry involved in using such materials often reinforces these psychological barriers. Unfamiliarity and the variety of forms add to some librarians' reluctance to accept responsibility for these materials.

Although professional librarians are capable of handling audio-visual materials and services, there are some skills and understandings that may present problems, such as the operation and maintenance of equipment, production techniques for aids not available com- mercially, and the instruction of students and faculty in the use of audiovisual media. The ideal solution to the personnel problem is the employment of a specially trained audio-visual librarian and an audio-visual clerk who can devote full time to this library service.

The audio-visual responsibility can be a large one, and many junior college libraries have a single librarian and a limited number of clerical assistants. The crux of the personnel problem lies in the philosophy, training, and ability of the librarian. In June 1961 the single librarian at Ventura College was observed handling audio-visual materials and equipment as well as other library operations in an easy, competent manner with the assistance of a well trained clerical staff.

Adequate space, facilities, and budgetary support are other important requisites that affect the quality of the audiovisual service. These, however, affect any such service wherever it is located. If the junior college audio-visual program is centralized in the library, there are principles and practices of administration, organization, and operation to guide the librarians.

The head librarian, who in many instances will be the only librarian, will be responsible for administering the program. The head librarian is usually responsible to the dean of instruction and ideally should be a member of the curriculum committee. The tasks of administration will be determined by the functions and services of the institution's audio-visual program. Whatever the scope may be, the usual elements of administration such as planning, budgeting, staffing, organizing, directing, and reporting are associated with the audiovisual service.

Although another librarian may be charged with carrying out the details of the program, the head librarian should 
have a sympathetic understanding of the role of audio-visual media in order to provide intelligent leadership and to inspire the staff to give good, effective audio-visual service to faculty and students. The library administrator should also be alert to trends and developments in this area and should profit from the experience of persons in the audio-visual field.

There should be a clear definition of policy as to the functions of the audiovisual center. In the development of plans for the college, representatives from the most AV-inclined departments should serve as an audio-visual committee to plan with the librarian. This committee may be a separate committee or a subcommittee of the faculty library committee. The audio-visual program should serve the particular curricular needs of the institution. The organization of the audio-visual service will be based on the particular program. Good service, including individual service to both faculty and students, should be a major objective. The program should be evaluated periodically in terms of its effective contribution to the teachinglearning process.

If an institution has not yet centralized its audio-visual materials and equipment, there should be a survey to determine what materials and equipment are available on campus. Existing information and comparative data should be used in planning the program. Many benefits may be gained from keeping some statistical records. The extent of use reflected in circulation records is a useful measure of the effectiveness of the program. Thus each junior college should study critically all aspects of its audio-visual program, and a committee composed of administrators, instructors, librarians, and audio-visual personnel should then formulate immediate and long-range plans based on the findings of the study.
The importance of trained personnel, both professional and clerical, has already been indicated. Junior college library standards specify that "If the audio-visual program is administered by the library, an additional trained staff member" should be provided. ${ }^{9}$ It is desirable to have professional librarians who are trained in both librarianship and audio-visual education. Good clerical assistance is needed to carry out the many routine operations. Student assistants may be utilized to good advantage. A pool of student projectionists may be helpful. The entire library staff should carry into practice a philosophy of service. In practice the professional personnel may evaluate and select materials and equipment; plan and supervise the production of materials; provide consultant services to instructors; give in-service training; carry out research studies; and handle public relations. The nonprofessional staff may handle the mechanical and technical phases of production; act as clerks and stenographers; receive and ship materials and equipment; catalog and file; service materials; and maintain equipment.

An adequate budget for materials and equipment contributes to a successful program. Junior college library standards state that if the audio-visual program is administered by the library, "an additional budget allotment should be provided."10 The responsibility for preparing and administering the audiovisual budget should rest with the librarian charged with administrative duties. The librarian will, of course, consult with the instructional and business leaders of the institution and the audiovisual committee. Like the library budget of which it may be a part, it will include provisions for salaries and wages, operating expenses, and capital outlay.

\footnotetext{
" "Standards for Junior College Libraries," op. cit., p.204. 10 Ibid.
} 
The audio-visual budget should justify itself in terms of its contribution to the total curriculum or institutional program.

A survey of California junior colleges for the 1956-57 academic year found audio-visual budgets that ranged from $\$ 100$ to $\$ 17,425$, with a per student expenditure of from ten cents to ten dollars, or an average of $\$ 3.30$ per student. ${ }^{11}$ The needs of individual departments is a dominant factor in deciding specific amounts. Some colleges allot money directly to the individual departments for the purchase of materials and equipment. A more general policy is to channel purchases and requests through the audio-visual center. A small four-year college reported that funds for each individual worked better than by departments after the audio-visual collection was started and equipment needs met. ${ }^{12}$

Adequate quarters and facilities are needed for carrying out the functions of an audio-visual service. Besides the circulation of materials, the range of services may include provision for projectors, record players, projectionist service, listening rooms, viewing rooms, recording service, photographic production, instruction, and reference and consultation. Junior college library standards specify space "for all services of the library, including . . . audio-visual quarters." ${ }^{13}$ The standards also state that "housing must be provided for special materials such as current periodicals, maps, pictures, art books, films, records, tapes, archives, and microprints." 14 Language laboratories and other listening facilities are often located in the library.

A well used audio-visual center is often a busy place. Outmoded buildings

\footnotetext{
11 Wetzler, op, cit., p.333.

${ }^{12}$ Edith P. Stickney and Henry Scherer, "Developing an A-V Program in a Small College Library," Library Journal, LXXXIV (September 1, 1959), 2457.

13 "Standards for Junior College Libraries," op. cit., p. 205 .

14 Ibid., p.204.
}

can present problems. In some cases, remodeling may be possible. Plans for new buildings should include provisions for the use of all types of audio-visual devices. In general, there should be space for four areas of operations: (1) an office for administrative functions; (2) library space for the storage and circulation of materials and equipment and for display; (3) a preview room for the selection and evaluation of materials and for other related purposes; and (4) workrooms for processing, maintenance, and local production of materials. ${ }^{15} \mathrm{Ar}-$ rangements should be flexible in order to provide for expansion and for a change of emphasis. Special fixtures of various kinds will be needed for storing various forms of materials.

The center should be organized to encourage maximum use. Convenience of service to faculty and students should be the principal consideration. Having an audio-visual desk always staffed during the hours of service promotes use. Keeping records, booking materials, and other operations that are repetitive, noncreative, mechanical, and/or routine should be kept to a minimum and reduced to their simplest form. Such procedures may be described in a handbook of operations, preferably a looseleaf manual, and re-examined at regular intervals to see if they can be eliminated or improved. The routine housekeeping details such as requesting material and equipment should not become a burden to the instructor, thereby inhibiting his potential utilization of the audio-visual services.

The variety of materials and equipment presents problems. Standards for selection and purchase should be established. Junior college library standards state that "audio-visual materials

\footnotetext{
${ }^{15}$ Francis W. Noel, "Principles of Administering Audio-Visual Programs," Audio-Visual Materials of Instruction (Forty-Eighth Yearbook of the National Society for the Study of Education, Part I [Chicago: University of Chicago Press]), pp.198-99.
} 
may include films, filmstrips, slides, tapes, recordings in music, drama, speech, and foreign languages. The same high standard of selection should be used as for books and other library materials. Faculty advice should be sought when needed."16 Some criteria for selecting audio-visual aids are: (1) the educational purpose of the material and the extent to which it will accomplish that purpose; (2) authenticity; (3) ease of operation or use; (4) cost; and (5) ease of repairs and replacement. ${ }^{17}$ The center should have an up-to-date collection of selection aids that are readily accessible for use by the entire junior college community, and pertinent items should be called to the attention of those instructors and/or departments that may be most interested.

Available funds, location of equipment, size of staff, number of classrooms, an institution's audio-visual emphasis, and community demands are factors in determining the nature of the audio-visual equipment. Sixteen millimeter projectors, record players, and $2 \times 2$ slide projectors are the most common kinds of equipment. Nontechnical maintenance may be performed by a combination of audio-visual staff and student help. Major repairs may be made by the distributor, college personnel, or an outside agency depending on circumstances. Equipment is usually stored in the audio-visual center and distributed to places of use as needed.

As in the case of materials, criteria should be established for the selection of each type of equipment. Some records giving useful information should be kept on each item of equipment: for example, inventory information; maintenance information; operational information. Replacements of equipment and materials should also receive attention. Out-of-date

\footnotetext{
16 "Standards for Junior College Libraries," op. cit., p.204.

${ }^{17}$ Lyle, op. cit., p.302.
}

materials should be weeded out of the collection with the assistance of the faculty.

On receipt, new materials should be classified, cataloged, and physically prepared for use. The nature of the material and the way in which it is to be used are factors in determining the procedure. The Dewey Decimal Classification system and the standard $3 \times 5$ catalog card are most frequently used. Whatever the system, it should make materials easily accessible and should allow for expansion and withdrawal in all subject areas. A unified catalog that includes all instructional materials regardless of format promotes maximum use.

Library of Congress printed cards are available and are often used for cataloging films, filmstrips, maps, records, slides, and tapes. Some libraries use different colored cards to indicate the various forms of materials. The format of the material may be indicated by a symbol that is placed above the classification number. Subject headings are based on the well known subject heading lists, and new headings may be taken from The Educational Film Guide or The Readers' Guide. Besides a title entry, there will be the necessary subject entries and cross references and a shelflist card.

At Mount San Antonio College audiovisual materials are cataloged on colored cards that are filed in the card catalog with the book entries. This system provides an index of all the instructional holdings of the college in one central place. ${ }^{18}$ Some institutions may desire to make two sets of catalog cards, one to file in the main card catalog, the other to file in a separate audio-visual catalog near the audio-visual service desk. Possibly, the audio-visual catalog should have each type of material in its own trays.

\footnotetext{
18 Harriett Genung, "The Heart of the College," Junior College Journal, XXIV (November 1953), 141.
} 
When the library staff obtains the material for the user, an identification number may be more satisfactory for arranging nonbook material than a subject classification number. This procedure makes it possible to arrange material in the order in which it is received; no space is wasted, and no shifting is necessary to fit new material into its proper place. In this case, a letter or letters would indicate the type of material, and a number would be given the material when it is received. This accession number would then be placed on the material, the shelflist, and the catalog card in place of a classification number. ${ }^{19}$

There are various aids that assist in readying audio-visual materials. For instance, the Special Libraries Association has a Loan Collection of Classification Schemes and Subject Heading Lists, which includes such subjects as films, maps, music, photographs, plates, postcards, slides, and video tapes. Some tools are entirely devoted to a particular type of material. Susan Akers' Simple Library Cataloging includes a list of abbreviations used in cataloging records, films, maps, and slides. ${ }^{20}$ Some materials, such as pictures and maps, call for special handling, but again there are guides to assist the librarian.

Before materials are placed in use, they should be prepared with the objectives of prolonging their life and of making them as usable as possible for students and instructors. Arrangements should be made for regular periodic cleaning, repair, and replacement.

These is considerable variation in practice regarding the shelving and storage of audio-visual material. Whatever the system for filing and storing, it should be orderly, easily expanded, flexible, and simple to operate. The amount of space available, whether instructors browse in

10 Susan Grey Akers, Simple Library Cataloging (4th ed.; Chicago: ALA, 1954), p.135.

${ }^{20}$ Ibid., p.148. the area, whether materials are distributed in packages, and personal preference are influential factors. There are many possible arrangements: by the Dewey Decimal Classification system; by curriculum areas; by types of materials, and so on.

Because effective use calls for the correct material at the right time, materials and equipment should be readily accessible. Convenience of service to instructors and students should underlie the system for requesting and circulating materials and equipment. Requests for materials, projection rooms, and equipment are usually handled by an audiovisual circulation desk. Regulations regarding pickup and return of materials may be included in a faculty handbook issued by the library or by the administration.

Simple clerical forms such as request forms for material and cards for charging out material and equipment facilitate service and save clerical time. Circulation records can provide useful information such as the relative demand for various titles, the average life of the kinds of audio-visual materials, the size and type of audience, and the needed information on which to base studies of this area of library service. Circulation statistics are valuable for various purposes. The development of the library as an audio-visual center may be guided by statistics. These may indicate the need for added, enlarged, or improved facilities, or for more or less equipment in certain buildings and departments, or they may also help to reinforce a budget request.

Although the library has central control of the equipment, some of the most needed equipment may be located elsewhere on campus through the use of a systematic checkout procedure that will indicate the location of each piece of equipment. Such a system will enable the library to service the equipment and 
to provide for its possible use elsewhere. In practice, circulation systems are determined by the size of the audio-visual collections, the frequency of use, and local conditions. Checkout systems vary; sign-up sheets, request blanks, and booking cards are popular. Some junior colleges use calendars, wall charts, or chalkboards. The experience of a small midwest college in developing an audiovisual center in the library is applicable to junior colleges. This library has an audio-visual desk that is always staffed and available for service. A schedule book is used to schedule equipment and materials, and to avoid conflicts in use. Materials in frequent use are housed behind the audio-visual circulation desk. This same institution also plans the use of films for the entire academic year, ahead of time, in order to provide adequately for scheduling and other details of arrangement. ${ }^{21}$

Local production of materials is an audio-visual function. While librarians may be able to fulfill most of the functions of an audio-visual center, however, local production when it involves such operations as photography often requires skills and facilities that the library and its staff cannot provide. It is feasible to provide materials and facilities in the library for picture mounting, poster and chart production, and for making recordings.

Instructors must know what materials are available and how to obtain them. Promoting the use of audio-visual materials and facilities is related to every phase of the audio-visual program. Use is the principal criterion in the organization of materials and equipment.

The faculty handbook is one means of promoting use within the college. It may outline the audio-visual services available and give information and directions for using the center. If the audio-visual collections are large, special book cata-

\footnotetext{
${ }^{2}$ Stickney and Scherer, op. cit., p.2458.
}

logs and listings may be prepared periodically. Subject folders help to bring related materials together. Lists of new audio-visual acquisitions may be duplicated and distributed to the faculty at regular intervals. An audio-visual bulletin board may be used to advantage. On occasion, departments or individual instructors should be notified about material of special interest to them. There should be some routing of information such as reviews to interested instructors. Various programs for promoting use should be planned and group and individual assistance and instruction given by the audio-visual staff.

What conclusions may we draw from this study of the concept of the junior college library as an audio-visual center? A junior college library may be responsible for administering the college's audio-visual program. There are many theoretical advantages to having these services centralized in the library, and junior college library standards cover the administration of these services by the library. In practice, the program can be a major undertaking, involving many complex operations and problems.

Trained personnel, both professional and clerical, are essential for good service. Junior college librarians should be familiar with audio-visual aids and devices and should adopt a positive attitude toward this area of library service. There is useful information in library, educational, and audio-visual literature to assist a librarian charged with the audio-visual responsibility. In any event, local factors of many kinds are certain to condition a particular junior college's audio-visual program. In short, it may be said that given trained personnel, sufficient funds for equipment and materials, and adequate physical facilities, a junior college librarian might well accept the challenge of the audio-visual responsibility as an opportunity to further the junior college objectives. 